\title{
A retrospective study of small molecule disorder types of metabolism in paediatric patients in intensive care
}

\author{
Ahmed El-Nawawy ${ }^{1}$, Mohamed Dawood ${ }^{1}$ and Omneya Omar ${ }^{1}$ \\ ${ }^{1}$ Department of Paediatrics, Faculty of Medicine, Alexandria University, Alexandria, Egypt (Correspondence to: Omneya M. Omar: drmonymagdy@ \\ yahoo.com).
}

\begin{abstract}
Background: Although inborn errors of metabolism (IEM) are rare individually, collectively IEM cause substantial morbidity and mortality and the diagnosis is challenging.

Aims: To analyse epidemiological and clinical data, final diagnosis and clinical outcomes of patients with a suspected diagnosis of IEM (small molecule disorders type) admitted to a paediatric intensive care unit (PICU).

Methods: We collected and analysed medical records data of all patients admitted to the PICU at Alexandria University Children's Hospital, from January 2010 to December 2014, with a suspected or confirmed diagnosis of small molecule disorders, including clinical presentations, laboratory results and clinical outcomes.

Results: A total of 34 patients had a suspected or confirmed diagnosis of small molecule disorders at PICU admission. Diagnosis was confirmed in $22.7 \%$ of suspected cases at admission and in $25 \%$ of suspected cases during PICU stay. Consanguineous marriage was found in $50 \%$ of cases with confirmed small molecule disorders.

Conclusions: A high index of suspicion is important for diagnosing and categorizing small molecule disorders in screening of high-risk individuals in low- and middle-income countries.

Keywords: small molecule disorders, inborn errors of metabolism, paediatric intensive care, consanguinity, organic acadaemia

Citation: El-Nawawy A; Dawood M; Omar O. A retrospective study of small molecule disorder types of metabolism in paediatric patients in intensive care. East Mediterr Health J. 2018;24(11):1103-1111. https://doi.org/10.26719/emhj.18.056
\end{abstract}

Received: 09/08/16; accepted: 27/02/18

Copyright (C) World Health Organization (WHO) 2018. Some rights reserved. This work is available under the CC BY-NC-SA 3.o IGO license (https:// creativecommons.org/licenses/by-nc-sa/3.o/igo).

\section{Introduction}

Inborn errors of metabolism (IEM) are a diverse heterogeneous group of inherited disorders that usually present in the paediatric population as varied clinical manifestations of defects in catabolism or anabolism of nutrients or energy-producing molecules. Although rare individually, collectively IEM cause substantial morbidity and mortality (1). They can be classified as disorders involving either large molecules (complexes or organelles) or small molecules. Organelle diseases are characterized by a gradual, often insidious, onset of symptoms, a relatively slowly progressive clinical course and specific clinical signs, which may be characteristic enough to make a diagnosis. Response to supportive therapy is generally only fair or poor. In contrast, IEM involving small molecules tend to be characterized by a rapid onset of symptoms and a clinical course featuring remissions and relapses. Physical findings are generally non-specific, which makes their diagnosis challenging at first presentation. However, small molecule disorders tend to respond well to aggressive supportive therapy (2).

Diagnosis of small molecule disorders is challenging due to the episodic nature of the metabolic illness, wide range of non-specific clinical symptoms also associated with common clinical conditions, general lack of experience among paediatric subspecialists and the need for expensive investigations (3).
No statistics on small molecule disorders of IEM are available in Egypt. The aim of this retrospective study was to analyse the epidemiological and clinical data, final diagnoses and clinical outcomes of patients admitted to the paediatric intensive care unit (PICU) at Alexandria University Children's Hospital with a suspected or confirmed diagnosis of small molecule disorders.

\section{Methods}

In this 5-year retrospective study, we collected medical records of all patients admitted to the PICU at El-Shatby Children's Hospital, a tertiary care teaching hospital affiliated to Alexandria University (serving 4 governorates comprising 14 million people), from 1 January 2010 to 31 December $2014(n=1417)$. Ages ranged from 1 month to 6 years. The policy of our hospital is that all cases of small molecule disorders presented at the emergency room are admitted to PICU. Inclusion criteria were: confirmed diagnosis of small molecule disorders and suspected diagnosis of small molecule disorders at the time of PICU admission or during PICU stay, with no subsequent confirmation of diagnosis (according to PICU protocol). The exclusion criterion was previous diagnosis of small molecule disorders in patients admitted to the PICU during the study period. Out of 1417 PICU admissions, 34 patients $(2.4 \%)$ had a suspected or confirmed small molecule disorder. 
To identify patients with suspected small molecule disorders and determine their management, according to our PICU policy, paediatric intensivists were required to enter specific information on patient symptoms and signs as well as laboratory investigations undertaken into a computer-based protocol. The symptoms and signs of clinical suspicion of small molecule disorders comprise a history of consanguinity, siblings with a history of similar illness or previous unexplained death, respiratory distress, apnoea, unexplained neurological symptoms, unexplained acute liver failure, feeding difficulties, failure to thrive, hepatomegaly and splenomegaly. Initial simple laboratory investigations performed immediately on admission to the PICU included random blood glucose, ketone bodies, arterial blood gases, anion gap, blood lactate, pyruvate and lactate/pyruvate ratio, blood ammonia and uric acid. Results from the laboratory investigations helped to classify small molecule disorders into 5 categories: aminoacidopathies, organic acidopathies, fatty acid oxidation defects, primary lactic acidosis and urea cycle defects.

From the medical records, we gathered demographic data, clinical data and laboratory findings suggesting small molecule disorders. Other data that were recorded by the residents were the Paediatric Index of Mortality 2 (PIM2) at admission, a scoring system for rating the severity of medical illness for children encompassing 10 physiological variables collected from the time of first physical contact between the patient and the PICU team up until 1 hour after physical PICU admission $(4,5)$, and paediatric logistic organ dysfunction (PELOD) score on day 2 in the PICU, a scoring system covering of physical and laboratory variables representing 6 organ systems: nervous, cardiovascular, renal, respiratory, haematologic and hepatic systems. Each variable is assigned points $(0,1,10$, or 20$)$ based on the level of severity, each organ dysfunction receives points for the variable associated with the highest number of points (6). The final diagnosis is documented as either a case of small molecule disorder (i.e. confirmed) or a non-small molecule disorder (i.e. not confirmed or proven to be an alternative diagnosis) and patient clinical outcome (i.e. PICU discharge, death or death within $\leq 24 \mathrm{~h}$ of PICU admission).

All data were analysed using SPSS, version 20.0 (7). The Kolmogorov-Smirnov test of normality revealed significance in the distribution of some variables, so the non-parametric statistics were adopted. Qualitative data are presented as numbers and percentages, and quantitative data as minimum, maximum, median and interquartile range (IQR). Comparison between different groups of category variables was made using the chisquared test. When $>20 \%$ of the cells had an expected count $<5$, correction for chi-squared was made using Fisher's exact test or the Monte Carlo correction.

Multivariate logistic regression analysis was done for prediction of mortality with PIM2 and PELOD as independent predictors. Area under the ROC Youden index (the vertical distance between the 45 degree line and the point on the ROC curve) was performed to determine the best cut-off value for the variable tested. Pair-wise comparison of areas under the ROC was carried out using MedCalc, version 14, for PIM2 and PELOD for discrimination for death $(8,9)$.

The calibration was assessed by directly comparing the observed and customized predicted mortality. We employed the Hosmer-Lemeshow goodness-of-fit test, where a $P$-value $>0.1$ indicates acceptable calibration (10).

\section{Results}

Out of 1417 PICU admissions from January 2010 to December 2014,34 patients $(2.4 \%)$ had a suspected or confirmed small molecule disorder. The age of onset ranged from 1.17 to 72.00 [median (IQR) 9.00 (2.88-24.00)] months. The male to female ratio was 1:1.27 (15:19 cases). Patient weight ranged from 1.55 to 20 [median (IQR) 7.00 $(4.78-10.25)] \mathrm{kg}$. Patient length of stay in PICU ranged from 1 to 26 [median (IQR) 3.50 (2.00-10.00)] days. PIM2 ranged from 20.00 to 90.80 [median (IQR) 44.95 (27.60$85.00)]$.The mortality rate in the study group $(18 / 34,52.9 \%)$ was more than twice the general mortality in the PICU at Alexandria University Children's Hospital (24.1\%).There were 7 deaths within $24 \mathrm{~h}$, and the PELOD score on day 2 for the remaining 27 cases ranged from 4 to 31 [median (IQR) 10.00 (5.00-20.00)] (Table 1).

Eight of the 34 cases $(23.5 \%)$ were confirmed as small molecule disorders, whether suspected on admission or not suspected on admission and subsequently confirmed during PICU stay. The diagnosis of small molecule disorders was confirmed in $22.7 \%$ of cases $(5 / 22)$ suspected on PICU admission, and in $25.0 \%$ of cases $(3 / 12)$ not suspected on PICU admission (Table 2). Of the 8 confirmed cases, 3 were diagnosed as organic acidaemia, 2 as urea cycle defects, 2 as aminoacidopathies and 1 as primary lactic acidosis. The best clinical outcome was obtained with cases of urea cycle defects and organic acidaemia where all patients, except 1 who died, were discharged.

A significantly higher rate of consanguinity was evident among cases confirmed as small molecule disorders compared to unconfirmed cases [4 cases $(50.0 \%)$ vs $3(11.5 \%)$ respectively, $P=0.037$. No statistically significant difference were found in terms of sex, age on presentation to PICU, history of sibling death in infancy (unknown cause or stillbirth) and place of residence (Table 3).

There was a significantly higher rate of jaundice in the confirmed compared with the non-confirmed small molecule disorders groups [ 3 cases $(37.0 \%)$ vs 1 case $(3.8 \%)$ respectively, $P=0.033$ ] (Table 4 ). In addition, from the laboratory results obtained from initial investigations on PICU admission, there was a significantly higher rate of hyperammonaemia and hyperuricaemia in the confirmed compared with the non-confirmed cases of small molecule disorders group [5 cases $(62.5 \%)$ vs 3 cases $(11.5 \%), P=0.009$, respectively; 7 cases $(87.5 \%)$ vs 8 cases $30.8 \%, P=0.011$, respectively] (Table 5). No other clinical presentations or laboratory results showed any statistically significant difference between the groups. 


\begin{tabular}{|c|c|}
\hline \multicolumn{2}{|c|}{$\begin{array}{l}\text { Table } 1 \text { Anthropometric and clinical data for patients } \\
\text { with suspected or confirmed diagnosis of small molecule } \\
\text { disorders on admission to a paediatric intensive care unit } \\
\text { (PICU) }(n=34)\end{array}$} \\
\hline Characteristic & Value \\
\hline \multicolumn{2}{|l|}{ Age at PICU presentation (months) } \\
\hline Min-max & $1.17-72.00$ \\
\hline Median (IQR) & $9.00(2.88-24.00)$ \\
\hline \multicolumn{2}{|l|}{ Sex, No. (\%) } \\
\hline Males & $15(44.1 \%)$ \\
\hline Females & $19(55.9 \%)$ \\
\hline \multicolumn{2}{|l|}{ Residence, No. (\%) } \\
\hline Rural & $19(55.9 \%)$ \\
\hline Urban & $15(44.1 \%)$ \\
\hline \multicolumn{2}{|l|}{ Weight (kg) } \\
\hline Min-max & $1.55-20$ \\
\hline Median (IQR) & $7.00(4.78-10.25)$ \\
\hline \multicolumn{2}{|c|}{ Paediatric Index of Mortality 2 (on admission) } \\
\hline Min-max & $20-90.80$ \\
\hline Mean (SD) & $53.10(27.14)$ \\
\hline Median (IQR) & $44.95(27.60-85.00)$ \\
\hline \multicolumn{2}{|l|}{ Length of stay (d) } \\
\hline Min-max & $1-26$ \\
\hline Mean (SD) & $6.97(6.11)$ \\
\hline Median (IQR) & $3.50(2.00-10.00)$ \\
\hline \multicolumn{2}{|l|}{ PELOD score on day $2^{a}$} \\
\hline Min-max & $4-31$ \\
\hline Mean (SD) & $13.52(8.03)$ \\
\hline Median (IQR) & $10.00(5.00-20.00)$ \\
\hline \multicolumn{2}{|l|}{ Outcome, No. (\%) } \\
\hline Discharged & $16(47.1)$ \\
\hline Died & $11(32.3)$ \\
\hline Died $\leq 24$ hours following admission & $7(20.6)$ \\
\hline
\end{tabular}

$I Q R=$ interquartile range.

PELOD score = Paediatric Logistic Organ Dysfunction score .

$S D=$ standard deviation.

${ }^{a} 7$ cases died $\leq 24$ hrs of admission

Min = minimum; Max $=$ maximum
Using the predictive model of mortality, examining the PIM2 and PELOD score as independent covariates, the classification accuracy of the model (block o, i.e. before implementation of the statistical model) was $59.25 \%$, with variations in the PELOD and PIM2 scores accounting for $50.1 \%$ of the variation of occurrence of death in the study sample $\left(-2\right.$ Log likelihood $=23.975$, Nagelkerke $R^{2}=0.501$ ). The regression model was well calibrated. The HosmerLemeshow $\chi^{2}$ value was $4.954(P=0.666)$. The overall model was statistically significant $\left(\chi^{2}=12.524, P=0.002\right)$ (independent covariates had predictive capacity). The predictive capacity of the model increased from $59.2 \%$ (of the basic "null" model) to $81.5 \%$. Only the PIM2 score was a statistically significant predictor of mortality [odds ratio $(\mathrm{OR})=1.050,95 \% \mathrm{CI}: 1.008-1.094](P=0.019)$. The PELOD score was not a statistically significant predictor of mortality $(\mathrm{OR}=1.100,95 \% \mathrm{CI}$ : $0.976-1.240)(P=0.118)$. (Table 6).

We found that PIM2 was a statistically significant discriminator of death: area under the ROC curve $=0.849$ (95\% CI: 0.685-0.948) $(Z=5.411, P<0.0001)$. The diagnostic criterion using the Youden index is the level of $>71.6$, with sensitivity $64.71 \%$ (95\% CI: $38.3-85.8$ ), specificity 94.12\% (95\% CI: $71.3-99.9$ ), positive predictive value $91.7 \%$ and negative predictive value $72.7 \%$. The PELOD score was a statistically significant discriminator of death: area under the ROC curve $=0.759$ (95\% CI: 0.556-0.901) $(Z=2.600, P=0.0093)$. The diagnostic criterion using the Youden index is the level of $>10.0$, with sensitivity $72.73 \%$ (95\% CI: 39.0-94.0), specificity $68.75 \%$ (95\% CI: $41.3-89.0 \%$ ), positive predictive value $61.5 \%$ and negative predictive value $78.6 \%$. Pair-wise comparison for the 2 ROC curves showed no statistically significant difference (Figure 1).

\section{Discussion}

Over 500 known IEMs, over 100 involving neonates, have been described (11). The frequencies for each individual IEM vary; although most are very rare, collectively they are common (12). In Egypt, 1 in every 32 individuals is reported to harbour a gene for an IEM (13). An extended metabolic screen carried out in 2004 on 231 suspected paediatric cases of IEM (44 neonates and 187 children) in Egypt revealed that abnormal results were detected in $8.56 \%(14)$.

Table 2 Relationship between status of provisional and final diagnoses

\begin{tabular}{|c|c|c|c|c|c|}
\hline \multirow[t]{3}{*}{ Provisional diagnosis } & \multicolumn{4}{|c|}{ Final diagnosis: small molecule disorder } & \multirow[t]{3}{*}{ Total } \\
\hline & \multicolumn{2}{|c|}{ Confirmed } & \multicolumn{2}{|c|}{ Not confirmed } & \\
\hline & $\begin{array}{l}\text { Suspected on } \\
\text { admission; } \\
\text { confirmed }\end{array}$ & $\begin{array}{l}\text { Not suspected } \\
\text { on admission; } \\
\text { confirmed later }\end{array}$ & $\begin{array}{l}\text { Suspected on } \\
\text { admission; not } \\
\text { confirmed }\end{array}$ & $\begin{array}{l}\text { Not suspected on } \\
\text { admission, became } \\
\text { suspected but not } \\
\text { confirmed }\end{array}$ & \\
\hline Not suspected No. (\%) & & $3(25.0 \%)$ & & $9(75.0)$ & 12 \\
\hline Suspected No. (\%) & $5(22.7)$ & & $17(77.3)$ & & 22 \\
\hline Total No. (\%) & \multicolumn{2}{|c|}{$8(23.5)$} & \multicolumn{2}{|c|}{$26(76.5)$} & 34 \\
\hline
\end{tabular}




\begin{tabular}{|c|c|c|c|c|c|}
\hline \multirow[t]{3}{*}{ Characteristic } & \multicolumn{4}{|c|}{ Small molecule disorders } & \multirow[t]{3}{*}{ P-value } \\
\hline & \multicolumn{2}{|c|}{ Confirmed cases $(n=8)$} & \multicolumn{2}{|c|}{ Not confirmed $(n=26)$} & \\
\hline & No. & $\%$ & No. & $\%$ & \\
\hline \multicolumn{6}{|l|}{ Sex } \\
\hline Male & 2 & 25.0 & 13 & 50.0 & 0.257 \\
\hline Female & 6 & 75.0 & 13 & 50.0 & \\
\hline \multicolumn{6}{|l|}{ Age at PICU presentation } \\
\hline Infant, 1-12 months & 5 & 62.5 & 15 & 57.7 & 1.000 \\
\hline Toddler, $12-36$ months & 3 & 37.5 & 8 & 30.8 & \\
\hline Preschool, 3-5 years & 0 & 0.0 & 2 & 7.7 & \\
\hline School age, $>5$ years & 0 & 0.0 & 1 & 3.8 & \\
\hline \multicolumn{6}{|l|}{ History of consanguinity } \\
\hline Yes & 4 & 50.0 & 3 & 11.5 & $0.037^{*}$ \\
\hline No & 4 & 50.0 & 23 & 88.5 & \\
\hline \multicolumn{6}{|c|}{ History of sibling death in infancy of unknown cause or stillbirth } \\
\hline Yes & 1 & 12.5 & 1 & 3.8 & 0.421 \\
\hline No & 7 & 87.5 & 25 & 96.2 & \\
\hline \multicolumn{6}{|l|}{ Residence } \\
\hline Rural & 4 & 50.0 & 15 & 57.7 & 1.000 \\
\hline Urban & 4 & 50.0 & 11 & 42.3 & \\
\hline \multicolumn{6}{|l|}{ Weight $^{a}$} \\
\hline Average & 2 & 25.0 & 8 & 30.8 & 0.440 \\
\hline Below 3rd percentile & 5 & 62.5 & 8 & 30.8 & \\
\hline Below 15th percentile & 1 & 12.5 & 8 & 30.8 & \\
\hline Above 85th percentile & 0 & 0.0 & 2 & 7.6 & \\
\hline \multicolumn{6}{|l|}{ Length ${ }^{a}$} \\
\hline Average & 2 & 25.0 & 4 & 15.4 & 0.783 \\
\hline Below 3rd percentile & 6 & 75.0 & 20 & 76.9 & \\
\hline Above 97th percentile & 0 & 0.0 & 2 & 7.7 & \\
\hline \multicolumn{6}{|l|}{ Head circumference $e^{a}$} \\
\hline Average & 3 & 37.5 & 15 & 57.7 & 0.655 \\
\hline Below 3rd percentile & 3 & 37.5 & 6 & 23.1 & \\
\hline Below 15th percentile & 2 & 25.0 & 4 & 15.4 & \\
\hline Above 85th percentile & 0 & 0.0 & 1 & 3.8 & \\
\hline \multicolumn{6}{|c|}{ History of affected cases among siblings } \\
\hline Yes & 1 & 12.5 & 0 & 0.0 & 0.235 \\
\hline No & 7 & 87.5 & 26 & 100.0 & \\
\hline
\end{tabular}

*Statistically significant, $P \leq 0.05$.

${ }^{a}$ Plot in specific curve using WHO percentiles (WHO child growth standards, 2006)

The majority of IEMs from various countries have been reported to be small molecule disorders. A study in Thailand showed that $74.3 \%$ of diagnosed IEM cases were small molecule disorders (15), and a 25 -year retrospective study in Saudi Arabia described a cumulative incidence of 150 IEM cases per 100 ooo live births (0.15\%), of which 54\% were small molecule disorders (16). The incidence of IEMs is reportedly lower in Western countries, e.g. 1 in 2500 live births (0.04\%) in British Columbia, Canada (17) and 1 in 2555 live births (0.04\%) in Italy (18). The difference may be related to consanguineous marriage and intermarriage.
In Egypt, the rate of consanguineous marriage is very high (35.3\%), especially among first cousins $(86 \%)$, and in rural areas, Upper Egypt and Cairo (19).

In our 5-year study, the incidence of suspected or confirmed cases of small molecule disorders was $2.4 \%$ (34/1417) of all PICU admissions, with only 8 confirmed cases of small molecule disorders of the 34 cases $(0.56 \%$ of all 1417 PICU admissions). This low incidence could be explained by a high pre-admission mortality rate of patients with small molecule disorders. This is comparable with the results from a 5-year study of PICU 


\begin{tabular}{|c|c|c|c|c|c|}
\hline \multirow[t]{3}{*}{ Characteristic } & \multicolumn{4}{|c|}{ Small molecule disorders cases } & \multirow[t]{3}{*}{$P$-value } \\
\hline & \multicolumn{2}{|c|}{ Confirmed $(n=8)$} & \multicolumn{2}{|c|}{ Non-confirmed $(n=26)$} & \\
\hline & No. & $\%$ & No. & $\%$ & \\
\hline Encephalopathy & 5 & 62.5 & 11 & 42.3 & 0.429 \\
\hline Unexplained neurological symptomsa & 3 & 37.5 & 12 & 46.2 & 1.000 \\
\hline Coma & 1 & 12.5 & 4 & 15.4 & 1.000 \\
\hline Fever & 2 & 25 & 10 & 38.5 & 0.681 \\
\hline Sepsis-like picture & 4 & 50 & 10 & 38.5 & 0.689 \\
\hline Respiratory distress & 3 & 37.5 & 12 & 46.2 & 1.000 \\
\hline Apnoea & 0 & 0.0 & 4 & 15.4 & 0.551 \\
\hline Vomiting & 5 & 62.5 & 11 & 42.3 & 0.429 \\
\hline Refusal of feeding & 1 & 12.5 & 7 & 26.9 & 0.645 \\
\hline Hepatomegaly & 5 & 62.5 & 11 & 42.3 & 0.429 \\
\hline Jaundice & 3 & 37.5 & 1 & 3.8 & $0.033^{*}$ \\
\hline Cardiac manifestationsb & 1 & 12.5 & 2 & $7 \cdot 7$ & 1.000 \\
\hline Splenomegaly & 1 & 12.5 & 0 & 0.0 & 0.2 \\
\hline
\end{tabular}

*Statistically significant, $P \leq 0.05$.

ancludes irritability, convulsion, hypotonia, hypoactive, history of ataxia and developmental delay.

${ }^{b}$ Cardiac manifestations mean heart failure.

\begin{tabular}{|c|c|c|c|c|c|}
\hline \multirow[t]{3}{*}{ Laboratory test } & \multicolumn{4}{|c|}{ Small molecule disorders cases } & \multirow[t]{3}{*}{ P-value } \\
\hline & \multicolumn{2}{|c|}{ Confirmed $(n=8)$} & \multicolumn{2}{|c|}{ Non-confirmed $(n=26)$} & \\
\hline & No. & $\%$ & No. & $\%$ & \\
\hline Hyperammonaemia & 5 & 62.5 & 3 & 11.5 & $0.009^{*}$ \\
\hline Hyperuricaemia & 7 & 87.5 & 8 & 30.8 & $0.011^{*}$ \\
\hline Hyperlactataemia & 4 & 50.0 & 6 & 23.1 & 0.195 \\
\hline High pyruvate & 1 & 12.5 & 1 & 3.8 & 0.421 \\
\hline High lactate/pyruvate ratio & 3 & 37.5 & 2 & 7.7 & 0.072 \\
\hline \multicolumn{6}{|l|}{ Arterial blood gas } \\
\hline Metabolic acidosis & 6 & 75.0 & 15 & 57.7 & \\
\hline Normal arterial blood gas & 0 & 0.0 & 3 & 11.5 & \\
\hline Respiratory acidosis & 0 & 0.0 & 2 & 7.7 & 0.903 \\
\hline Compensated respiratory alkalosis & 2 & 25.0 & 6 & 23.1 & \\
\hline Blood glucose & & & & & 0.133 \\
\hline Normal & 3 & 37.5 & 11 & 42.3 & \\
\hline Hypoglycaemia & 3 & 37.5 & 2 & 7.7 & \\
\hline Hyperglycaemia & 2 & 25.0 & 13 & 50.0 & \\
\hline Ketononuria & 3 & 37.5 & 2 & 7.7 & 0.072 \\
\hline
\end{tabular}

*Statistically significant, $P \leq 0.05$.

admissions in a French teaching hospital (incidence $2.2 \%$ of all PICU admissions) (20) and a 1-year PICU study in India (incidence $2.6 \%$ of all PICU admissions) of suspected or diagnosed IEM, including small molecule disorders (21).

In a study from Brazil, only $6.7 \%$ (4/59) of suspected cases admitted to the PICU were diagnosed as IEM (22).
In contrast, in a 3 -year study in Pakistan $26 \%$ of suspected cases were diagnosed as IEM, including small molecule disorders (23). In our study, 1.5\% (22/1417) of all PICU admissions were suspected cases of IEM, and only $22.7 \%$ (5/22) of these were confirmed to be small molecule disorders.

In developed countries, small molecule disorders 
Table 6 Multivariate logistic regression analysis for predicting mortality in children with small molecule disorders on admission to paediatric intensive care, January 2010-December 2014

\begin{tabular}{lcccc} 
Predictor & B & P-value & OR & 95\% CI \\
PIM2 & 0.049 & 0.019 & $1.050^{*}$ & $1.008-1.094$ \\
PELOD score & 0.095 & 0.118 & 1.100 & $0.976-1.240$ \\
\hline
\end{tabular}

*Statistically significant, $P \leq 0.05$.

Constant $=-4.273$

OR $=$ odds ratio.

$C I=$ confidence interval.

$\mathrm{PIM} 2$ = paediatric index of mortality 2 .

PELOD = paediatric logistic organ dysfunction .

are typically diagnosed using high-performance liquid chromatography (HPLC) and tandem mass spectrophotometry (3). Gas chromatography/mass spectroscopy is an advanced technique for diagnosing and confirming metabolic disorders and also for mass neonatal screening (18). Enzyme assays with leukocytes or erythrocytes are used to confirm a specific enzyme deficiency (3). These diagnostic techniques are expensive and beyond the financial capacity of many developing countries. Therefore, in developing countries, diagnosis of IEM relies on simple clinical and laboratory tests for the selective screening of high-risk individuals suspected of IEM, in order to identify the small molecule disorders so that early empirical supportive treatment can be initiated. This approach is often supported by other approaches to confirm the final diagnosis. For example, in Thailand, clinicians work in collaboration with the Chulabhorn Research Institute in Bangkok for the use of high-performance liquid chromatography (15), and in Pakistan (23) and Saudi Arabia (16) samples are sent to specialized laboratories in Japan and the United
States, respectively, to confirm the final diagnosis. Thus, screening for IEM without primary selection is a costly process for developing countries with limited resources. Patients with small molecule disorders are usually diagnosed following PICU admission and are considered acute emergencies amenable to lifesaving therapy (20). However, their prognosis is very poor due to the delay in diagnosis and management (15). Therefore, small molecule disorders warrant heightened attention, as early diagnosis is essential for early treatment and improved clinical outcome.

A French study reported a mortality rate of $28.6 \%$ (20/70) of confirmed IEM cases among PICU admissions, which was twice that observed for all PICU admissions and 4 times that observed in European PICUs (20). A retrospective study in Italy reported a PICU mortality rate of $25.3 \%$ of confirmed IEM cases (18). A study from India found a mortality rate of $36 \%$ among PICU admissions of confirmed IEM cases (21). Consistent with these findings from previous studies, in our study, the mortality rate among the 34 patients we studied was $52.9 \%$, whereas the

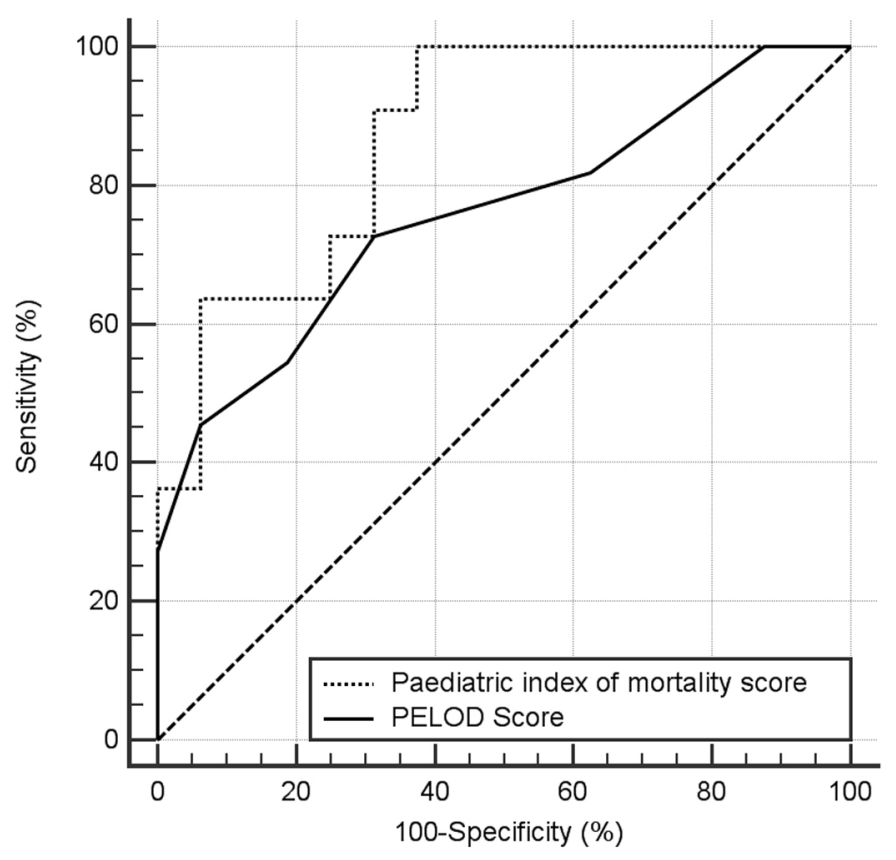

Figure 1 Area under the receiver operator characteristics (ROC) curve: comparison of paediatric index of mortality (PIM2) and paediatric logistic organ dysfunction (PELOD) score for discriminating outcomes (the dashed line represents a non-discriminatory test) 
mortality rate among confirmed cases of small molecule disorders was $37.5 \%(3 / 8)$, which was higher than our total PICU mortality rate of $24.1 \%$. We should, however, take into consideration the very small number in the sample. The high mortality rate may be due to delayed diagnosis, encephalopathy, respiratory distress, heart failure or dehydration.

The rate of various clinical presentations did not show any statistically significant differences between confirmed and non-confirmed small molecule disorders groups, except for the presence of jaundice, which was significantly higher in the confirmed groups. This may be explained by the presence of severe illness in patients with small molecule disorders, who usually present with multiple organ dysfunction syndromes, including pre-hepatic failure, which manifests as jaundice. Our finding is in contrast to those of a prior report in which about half of the IEM patients, including those with small molecule disorders, had acute encephalopathy as the most common clinical presentation (15). A 3-year study in Pakistan showed that respiratory distress and developmental delay were the most common clinical presentations in cases diagnosed with IEM, including small molecule disorders (23). This difference could be explained by the variability of symptoms and severity and the non-specificity of small molecule disorders.

Comparison of laboratory results between confirmed small molecule disorders and not confirmed cases revealed a significantly higher rate of hyperammonaemia and hyperuricemia in the confirmed group. This may be because of urea cycle defects and organic acidaemia, which represented $62.5 \%$ (5/8) of cases, usually present with hyperammonaemia. This finding is in agreement with prior findings of a significantly higher rate of hyperammonaemia in the IEM group, including small molecule disorders, compared to the non-IEM group, although, contrary to our findings, metabolic acidosis and ketosis were also found to be frequent (15).

We evaluated the performance of the PELOD score compared with PIM2 for predicting mortality in small molecule disorders in PICU; most research uses these scores generally for survival in PICU $(24,25)$, however in our study, only the PIM2 score was a statistically significant predictor of mortality. Similarly, a 2013 study in India reported the under-prediction of mortality by PELOD-2 compared to PIM2 (24); it is possible that the predictive mortality models could be population sensitive, so validation studies are necessary before application in other settings and populations.

A limitation of our study is the small sample size; this ensues from the rarity of small molecule disorders.

Funding: None.

Competing interests: None declared.

\section{Étude rétrospective des maladies du métabolisme des petites molécules chez les patients pédiatriques admis aux soins intensifs}

\section{Résumé}

Contexte : Si les erreurs innées du métabolisme (EIM) sont rares au plan individuel, elles sont collectivement à l'origine d'une morbidité et d'une mortalité élevées. Elles sont en outre difficiles à diagnostiquer.

Objectifs : La présente étude visait à analyser les données épidémiologiques et cliniques, les diagnostics définitifs et les résultats cliniques des patients ayant un diagnostic suspecté d'EIM (de la catégorie des troubles du métabolisme des petites molécules) admis dans une unité de soins intensifs pédiatriques (USIP).

Méthodes : Nous avons recueilli et analysé les données des dossiers médicaux de tous les patients admis à l'USIP de l'hôpital universitaire pour enfants d'Alexandrie entre janvier 2010 et décembre 2014 ayant un diagnostic suspecté ou confirmé de troubles du métabolisme des petites molécules, y compris les manifestations cliniques, les résultats de laboratoire et les résultats cliniques.

Résultats: Au total, 34 patients avaient un diagnostic suspecté ou confirmé de troubles du métabolisme des petites molécules au moment de leur admission à l'USIP. Le diagnostic a été confirmé au moment de l'admission dans $22,7 \%$ des cas suspectés et pendant le séjour à l'USIP dans $25 \%$ des cas suspectés. Le mariage consanguin a été associé à $50 \%$ des cas confirmés de troubles du métabolisme des petites molécules.

Conclusion : Le diagnostic et la classification des troubles du métabolisme des petites molécules chez les individus à risque vivant dans les pays en développement exigent un indice de suspicion élevé.

$$
\begin{aligned}
& \text { در اسة استرجاعيّة لأنواع اضطر ابات الجزيئات الصغيرة في أمر اض التمثيل الأيضى لدى المرضى من الأطفال في وحدة }
\end{aligned}
$$

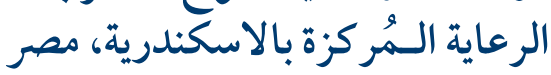

$$
\begin{aligned}
& \text { أحمد النو اوي، محمد داوود، أمنية عمر الحمره } \\
& \text { الخلاصة }
\end{aligned}
$$

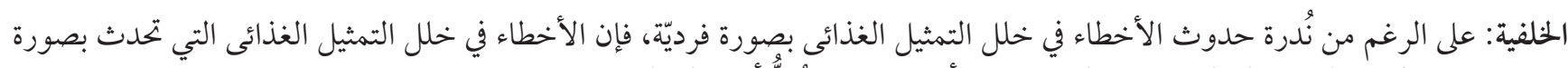

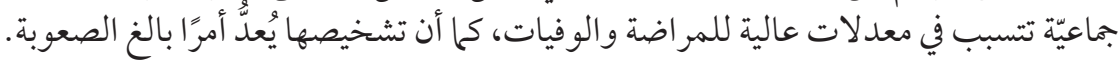




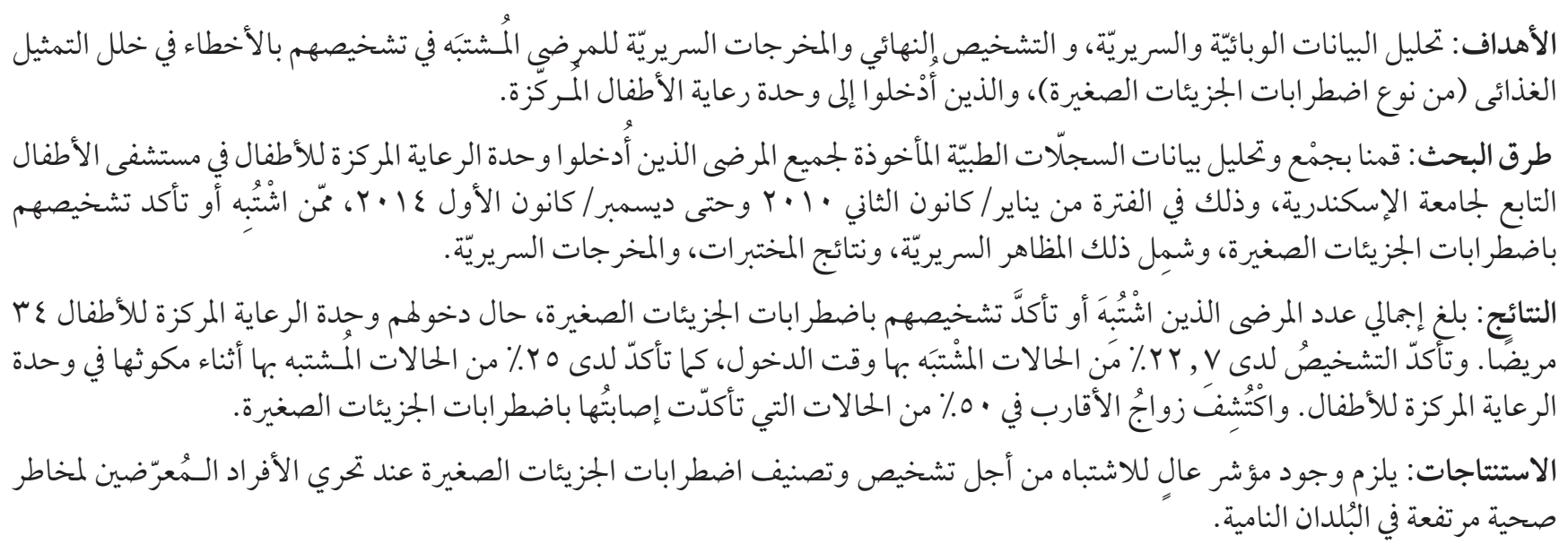

\section{References}

1. Kumta NB. Inborn errors of metabolism (IEM) - an Indian perspective. Indian J Pediatr. 2005 Apr;72(4):325-32. https://doi. org/10.1007/BF02724016

2. Clarke J. A stepwise clinical approach to inherited metabolic diseases. HK J Paediatr. 2004;9(3):261-7.

3. Rao AN, Kavitha J, Koch M, Suresh Kumar V. Inborn errors of metabolism: Review and data from a tertiary care center. Indian J Clin Biochem. 2009 Jul;24(3):215-22. https://doi.org/10.1007/s12291-009-0041-y PMID:23105838

4. Slater A, Shann F, Pearson G; Paediatric Index of Mortality (PIM) Study Group. PIM2: a revised version of the Paediatric Index of Mortality. Intensive Care Med. 2003 Feb;29(2):278-85. https://doi.org/10.1007/s00134-002-1601-2 PMID:12541154

5. Netto AL, Muniz VM, Zandonade E, Maciel ELN, Bortolozzo RN, Costa NF, et al. Desempenho do Pediatric Index of Mortality 2 em unidade de cuidados intensivos pediátrica [Performance of the Pediatric Index of Mortality 2 in a pediatric intensive care unit]. Rev Bras Ter Intensiva. 2014 Jan-Mar;26(1):44-50. https://doi.org/10.5935/0103-507X.20140007 PMID:24770688

6. Leteurtre S, Duhamel A, Grandbastien B, Proulx F, Cotting J, Gottesman R, et al. Daily estimation of the severity of multiple organ dysfunction syndrome in critically ill children. CMAJ. 2010 Aug 10;182(11):1181-7. https://doi.org/10.1503/cmaj.081715 PMID:20547715

7. Kirkpatrick LA, Feeney BC, editors. A simple guide to IBM SPSS statistics for version 20.0. 12th ed. Belmont (CA): Wadsworth, Cengage Learning; 2013.

8. DeLong ER, DeLong DM, Clarke-Pearson DL. Comparing the areas under two or more correlated receiver operating characteristic curves: a nonparametric approach. Biometrics. 1988 Sep;44(3):837-45. https://doi.org/10.2307/2531595 PMID:3203132

9. Schoonjans F, Zalata A, Depuydt CE, Comhaire FH. MedCalc: a new computer program for medical statistics. Comput Methods Programs Biomed. 1995 Dec;48(3):257-62. https://doi.org/10.1016/0169-2607(95)01703-8 PMID:8925653

10. Keegan MT, Gajic O, Afessa B. Severity of illness scoring systems in the intensive care unit. Crit Care Med. 2011 Jan;39(1):163-9. https://doi.org/10.1097/CCM.obo13e3181f96f81 PMID:20838329

11. Saudubray JM, Nassogne MC, de Lonlay P, Touati G. Clinical approach to inherited metabolic disorders in neonates: an overview. Semin Neonatol. 2002 Feb;7(1):3-15. https://doi.org/10.1053/siny.2001.0083 PMID:12069534

12. Scalco FB, Oliveira MLC, Simoni RE, Aquino Neto FR. Inborn errors of metabolism, an important group of orphan neglected diseases:Investigation of 8,000 patients in Rio de Janeiro, Brazil. J Braz Chem Soc. 2014;25(10):1914-7. http://dx.doi.org/10.5935/01035053.20140203

13. Hashem N. Thalassemia syndromes and other haemoglobinopathies prevalent among Egyptians. In: Proceedings of the first international conference on preventable aspects of genetic morbidity, vol. 1. Cairo, Egypt; 1978:54-7.

14. Elsobky E, Elsayed SM. Extended metabolic screen in sick neonates and children. Egypt J Med Hum Genet. 2004;2(2):71-91.

15. Wasant P, Vatanavicharn N, Srisomsap C, Sawangareetrakul P, Liammongkolkul S, Svasti J. Retrospective study of patients with suspected inborn errors of metabolism at Siriraj Hospital, Bangkok, Thailand (1997-2001). J Med Assoc Thai. 2005 Jun;88(6):74653. PMID:16083213

16. Moammar H, Cheriyan G, Mathew R, Al-Sannaa N. Incidence and patterns of inborn errors of metabolism in the Eastern Province of Saudi Arabia, 1983-2008. Ann Saudi Med. 2010 Jul-Aug;30(4):271-7. https://doi.org/10.4103/0256-4947.65254 PMID:20622343

17. Applegarth DA, Toone JR, Lowry RB. Incidence of inborn errors of metabolism in British Columbia, 1969-1996. Pediatrics. 2000 Jan;105(1):e10. https://doi.org/10.1542/peds.105.1.e10 PMID:10617747

18. Dionisi-Vici C, Rizzo C, Burlina AB, Caruso U, Sabetta G, Uziel G, et al. Inborn errors of metabolism in the Italian pediatric population: a national retrospective survey. J Pediatr. 2002 Mar;140(3):321-9. https://doi.org/10.1067/mpd.2002.122394 PMID:11953730

19. Shawky RM, Elsayed NS, Ibrahim DS, Seifeldin NS. Profile of genetic disorders prevalent in northeast region of Cairo, Egypt. Egypt J Med Hum Genet. 2012;3:45-62. https://doi.org/10.1016/j.ejmhg.2011.10.002 
20. Jouvet P, Touati G, Lesage F, Dupic L, Tucci M, Saudubray JM, et al. Impact of inborn errors of metabolism on admission and mortality in a pediatric intensive care unit. Eur J Pediatr. 2007 May;166(5):461-5. https://doi.org/10.1007/s00431-006-0265-2 PMID:16941128

21. Kamate M, Chetal V, Kulgod V, Patil V, Christopher R. Profile of inborn errors of metabolism in a tertiary care centre PICU. Indian J Pediatr. 2010 Jan;77(1):57-60. https://doi.org/10.1007/s12098-010-0008-2 PMID:20135269

22. Wajner M, Wannamacher C, Gaidzinski D. Detection of inborn errors of metabolism in patients of pediatric intensive care units of Porto Alegre, Brazil: comparison of the prevalence of such disturbances in a selected and an unselected sample. Brazil J Genet. 1986;9:331-40.

23. Satwani H, Raza J, Hanai J, Nomachi S. Prevalence of selected disorders of inborn errors of metabolism in suspected cases at a tertiary care hospital in Karachi. J Pak Med Assoc. 2009 Dec;59(12):815-9. PMID:20201170

24. Gandhi J, Sangareddi S, Varadarajan P, Suresh S. Pediatric index of mortality 2 score as an outcome predictor in pediatric Intensive Care Unit in India. Indian J Crit Care Med. 2013 Sep;17(5):288-91. https://doi.org/10.4103/0972-5229.120320 PMID:24339640

25. El-Nawawy A, Mohsen AA, Abdel-Malik M, Taman SO. Performance of the pediatric logistic organ dysfunction (PELOD) and (PELOD-2) scores in a pediatric intensive care unit of a developing country. Eur J Pediatr. 2017 Jul;176(7):849-55. https://doi. org/10.1007/s00431-017-2916-x PMID:28492972 